\title{
Representações sociais dos estudantes do ensino básico no desenvolvimento turístico na cidade de Bonito (MS)
}

\section{Social representations of students in basic education in tourism development in the city of Bonito (MS, Brazil)}

\author{
Clara Antunes Cardoso, Emerson Machado de Carvalho, \\ Luciana Ferreira da Silva
}

\section{RESUMO}

O município de Bonito está localizado a sudoeste do Mato Grosso do Sul na microrregião geográfica Bodoquena, tendo a pecuária e o turismo como principais atividades econômicas. Através do ecoturismo o município tem buscado promover o desenvolvimento nas áreas sociais, econômicas e ambientais. Assim, a presente pesquisa procurou avaliar a percepção dos estudantes do ensino básico ( $8^{\circ}$ e $9^{\circ}$ anos) de uma escola municipal sobre 0 desenvolvimento turístico na região e a necessidade de inserção de visita técnica orientada na disciplina curricular "Noções Básicas do Turismo". A disciplina está presente na grade curricular desde 2006, porém não promove regularmente atividades em campo. Para levantamento dos dados foi utilizada entrevista semiestruturada e o Teste de Associação Livre de Palavras (TALP) e analisadas segundo o Discurso do Sujeito Coletivo (DSC) e a Teoria das Representações Sociais (TRS). Apesar dos estudantes terem sido favoráveis ao desenvolvimento do turismo na região de Bonito, poucos demonstraram envolvimento direto ou indireto com as atividades turísticas. No entanto, os estudantes demonstraram ter conhecimento e uma relação afetiva com a fauna local, garantindo assim a promoção da educação ambiental, sobretudo na visita orientada, para que as mesmas não tenham apenas o enfoque de lazer. A experiência com a visita orientada também permitiu o resgate da identidade da coletividade, através da afinidade e forte interação que os estudantes demonstraram com o meio ambiente. Estes resultados, entretanto, indicaram a necessidade da inserção das visitas técnicas orientadas aos atrativos turísticos de Bonito como base metodológica nas atividades escolares.

PALAVRAS-CHAVE: Ecoturismo; Educação Ambiental; Turismo de Estudos; Turismo Pedagógico. 


\section{ABSTRACT}

The city of Bonito is located in southwestern Mato Grosso do Sul in the Bodoquena region. The economy consists primarily of ranching and tourism. Through tourism, the town has sought to promote social, economic and environmental development. This study sought to assess the perception of students in their $8^{\text {th }}$ and $9^{\text {th }}$ years at a public school regarding the development of tourism in the region and the need to include a field trip related to their "Basic Concepts of Tourism" course. The class has been present in the curriculum since 2006, but does not include routine field trips. A semi-structured interview and the Free Word Association Test (TALP) were used to collect data, and the data were analyzed using Collective Discourse of the Subject (DSC) and the Social Representations Theory (TRS). Although students felt favorably toward the development of tourism in Bonito, few demonstrated direct or indirect involvement in tourism activities. However, students demonstrated knowledge of and concern for the local wildlife, thus guaranteeing support for environmental education, as noted during the visit during which students were not focused solely on having fun. The guided visit also allowed for the development of a collective identity through the affinity and deep interaction the students demonstrated with the environment. These results, however, suggest the need to include methodology-based guided field trips to Bonito's tourist attractions in the school curriculum.

KEYWORDS: Ecotourism; Environmental Education; Educational Tourism; Pedagogical Tourism.

\section{Introdução}

O turismo é um fenômeno socioeconômico dinâmico que abrange as áreas social, cultural e ambiental de uma localidade (RODRIGUES, 2001) e, no entanto, pode ser geradora de renda para os diferentes grupos envolvidos, não apenas para as empresas organizadoras, mas também para as comunidades anfitriãs (PELICIONI; TOLEDO, 2010).

Segundo a Política Nacional de Turismo (BRASIL, 1992), o turismo apresenta, entre as diretrizes de planejamento, metas como "reduzir as disparidades sociais e econômicas de ordem regional, através do crescimento da oferta de emprego e melhor distribuição de renda". Neste contexto, para além das empresas, o turismo precisa do envolvimento de órgãos públicos, para planejar e organizar, e da inclusão da comunidade local, com programas de sensibilização, valorização, capacitação e treinamento. De acordo com o Manual para políticas locais (WWF-Brasil, 2004), a "educação, conscientização e capacitação compõem a base do turismo responsável". Consequentemente, o manual aponta que "todos os integrantes do setor devem ser alertados sobre seus impactos positivos e negativos e encorajados a serem responsáveis e apoiar a conservação por meio de suas atividades".

No entanto, é importante que a conscientização e aprendizagem sejam viabilizadas pelos órgãos responsáveis pelo turismo e que os mesmos capacitem e ofereçam recursos para que os autóctones façam parte do processo de implantação e manutenção da atividade, pois eles conhecem as verdadeiras fragilidades e potencialidades de sua região (SALUSTIANO et 
al., 2007). Quando a comunidade é mobilizada para o desenvolvimento do turismo, a mesma motiva-se a participar das ações e ganhos e ajuda a gerenciar os impactos sobre a localidade.

A população de uma localidade turística precisa entender e ver benefícios da atividade sendo realizada, pois são essas pessoas que irão vivenciar, trabalhar e interagir com as empresas, instituições e turistas. Assim, o empreendimento turístico pode ser concebido como um produto da cultura, ou seja, a complexidade de seu entendimento é mais bem contemplada pelo enfoque cultural e não apenas com explicações de caráter econômico, como ao longo da evolução teórica do turismo foram feitas, sendo estas definições reducionistas e limitadas (FONSECA, 2007).

As atividades turísticas organizadas, quando bem interagidas com 0 meio ambiente natural e cultural, promovem maiores ofertas de empregos e receitas, trazendo melhorias para comunidade anfitriã (RUSCHMANN; SOLHA, 2004). E os benefícios, além de econômicos, também são estruturais, mais opções de lazer, intercâmbio cultural, ou seja, uma atividade turística bem desenvolvida promove melhoria significativa na qualidade de vida dos moradores. Tendo em vista essas considerações, entende-se que é necessário dotar-se de ferramentas adequadas para promover e executar ações de inserção da comunidade no processo turístico.

Enquanto o turismo é uma atividade de mercado que instiga o consumo, tentando amenizar seus impactos (socioambientais) através de discursos ambientalistas superficiais, a Educação Ambiental necessita de outras ferramentas para acontecer (SANDEVILLE-JR; SUGUIMOTO, 2010). É importante compreender que a formação de uma consciência ambientalista se dá não apenas por meio da interpretação da natureza ou da promoção do bem-estar das populações envolvidas, mas, principalmente pela Educação Ambiental (PELICIONI; TOLEDO, 2010). Assim, ela tem sido apresentada como uma ferramenta significativa na promoção de um turismo sustentável e, principalmente, uma eficiente metodologia participativa de intervenção nas comunidades.

Um importante aspecto a se considerar numa abordagem de Educação Ambiental está no entendimento da percepção do educando, visando sua inserção crítica na realidade. Entende-se que o contato esporádico do ser humano com a natureza não é o suficiente para justificar uma mudança de comportamento perante as questões ambientais, uma vez que este indivíduo está cotidianamente envolvido por um contexto imerso nos valores de uma sociedade que segue a lógica do capital, ou seja, da produção e do consumo (RODRIGUES, 2010). No entanto, ao compreender os valores, opiniões, mitos, crenças e atitudes de uma comunidade torna-se possível sugerir estratégias para o desenvolvimento do turismo com base na sustentabilidade e as atividades turísticas como instrumento de valorização da cultura local e afirmação da identidade (REIS; BOMFIM, 2012).

Estudantes de escolas públicas e privadas, por serem agentes multiplicadores de informações, são importantes sujeitos para garantir o sucesso de programas de Educação ambiental. No entanto, a presente pesquisa está fundamentada na percepção de estudantes do ensino 
fundamental sobre o desenvolvimento do turismo de natureza no município de Bonito, Mato Grosso do Sul.

A região de Bonito, localizada no centro-oeste brasileiro do estado de Mato Grosso do Sul, tornou-se a região mais visitada no turismo de natureza nos últimos anos no Brasil (OLIVEIRA, 2011) e desenvolve o ecoturismo como uma das principais atividades econômicas. O município pode ser classificado como uma área turística de caráter regional e nacional, em função do grande número de atrativos que oferece, principalmente naturais (MARIANI, 2003).

O município está localizado na microrregião geográfica Bodoquena, sudoeste do estado de Mato Grosso do Sul, com área territorial de 4.934 $\mathrm{km}^{2}$ e uma população absoluta, em 2004, de 17.861 habitantes (GRECHI et al., 2010). A bacia do Rio Miranda é a principal na região envolvendo rios como Formoso, Peixe, Prata, Mimoso e Anhumas (FASSINI; LACERDA, 2009), entre outros rios subterrâneos, sumidouros, cascatas, ressurgências, crateras com águas cristalinas, resultado da grande quantidade de calcário dissolvido. Todo esse conjunto proporciona grande beleza cênica às paisagens naturais da região.

Em 2006, o município inseriu como obrigatoriedade na grade curricular do $8^{\circ}$ e $9^{\circ}$ ano das escolas municipais a disciplina de "Noções Básicas do Turismo", conforme Projeto de Lei Ordinária ㄲo․ 16/2006 (BONITO, 2006), iniciando a epistemologia turística na educação básica escolar. Para Castro (2008), envolver turismo e educação "é um dos instrumentos básicos para a transposição de barreiras na área turística" na intenção de permitir a participação da comunidade local através do planejamento e esforço de todos os agentes envolvidos no turista. $\mathrm{O}$ autor ainda ressalta que essa interação transforma a comunidade em protagonista, sendo ela a responsável pela divulgação e conhecimentos das riquezas locais, dando identidade e sendo o diferencial do destino turístico.

$\mathrm{Na}$ presente pesquisa optou-se por trabalhar com uma parcela da comunidade que cursa a educação escolar básica de Bonito. Para atingir os objetivos propostos, primeiramente foi realizada uma visita orientada a um atrativo turístico com intenção de desenvolver uma atividade de educação turística e ambiental. Esse tipo de atividade pode ser executada de maneira formal ou informal, sendo a formal nas unidades de ensino no âmbito curricular, e informal, no que se refere a presente atividade, pois se realizou fora da escola, com atividades educativas, sensibilizando a coletividade (SALUSTIANO et al., 2007). O segundo passo foi aplicar um questionário aos estudantes, antes e após a visita orientada, com o auxilio de metodologias como o teste de associação livre de palavras (TALP), a análise do Discurso do Sujeito Coletivo (DSC) e a Teoria das Representações Sociais (TRS).

Para tanto, será avaliada a necessidade de inserção da visita orientada na disciplina curricular, como forma de promover a interdisciplinaridade entre as matérias e os temas relacionados a turismo e meio ambiente aos estudantes. 


\section{Metodologia}

A presente pesquisa trata-se de um estudo qualitativo, do tipo exploratório-descritivo, sendo realizada em quatro etapas: (1) análise da percepção dos estudantes sobre turismo e desenvolvimento local através do teste de associação livre de palavras; (2) análise do DSC e TRS dos estudantes sobre a importância do turismo no desenvolvimento local; (3) visita orientada de turismo educativo em pontos turísticos de Bonito (Fazenda Mimosa) como parte da disciplina "noções básicas de turismo" e; 4) avaliação da percepção e análise do DSC e TRS após a visita técnica.

\section{Local e população de estudo}

A pesquisa contou com a participação de 26 estudantes do $8^{\circ}$ e $9^{\circ}$ anos da Escola Municipal João Alves de Arruda, acompanhados pela Coordenadora Pedagógica e da Professora responsável pela disciplina "Noções básicas de turismo", lecionada para as duas turmas.

A visita técnica ocorreu no atrativo turístico Estância Mimosa, localizada na Rodovia Bonito/Bodoquena Km 24. O local foi selecionado por se tratar de um passeio de trilha e cachoeira ideal para ter mais interação entre guia de turismo e estudante, além de ser um atrativo com ótima infraestrutura e com profissionais qualificados, garantindo ainda mais 0 sucesso da atividade. A visita teve duração de 4 horas, incluindo o tempo de deslocamento que demorou aproximadamente uma hora e meia entre ida e retorno. Os estudantes puderam participar da atividade de trilha interpretativa em mata bem preservada com paradas em cachoeiras do Rio Mimoso e visitas a locais como Cachoeira do Desejo, Cachoeira do Salto e Cachoeira da Figueira. Além dessas atividades, os instrutores, ou seja, três guias de turismo e dois turismólogos abordaram conceitos relacionados ao sistema turístico do passeio, a interação com turistas, o sistema de gestão de segurança e os equipamentos utilizados na atividade (colete salva-vidas e bota de neoprene). Durante a trilha os guias passaram informações sobre as características ambientais da localidade. Todos os assuntos abordados na atividade foram previamente planejados e identificados na ementa da disciplina de noções básicas do turismo.

\section{Técnica de Associação Livre de Palavras}

Para investigação da percepção dos estudantes acerca do tema "turismo e desenvolvimento local" foi aplicado a Técnica de Associação Livre de Palavras (TALP) para 10 estudantes do $8^{\circ}$ ano e 15 estudantes do $9^{\circ}$ ano, utilizando a seguinte expressão indutora: "O turismo em Bonito é...".

A TALP foi originalmente desenvolvida na prática clínica e atualmente é utilizado no campo da psicologia social nas pesquisas sobre representações sociais (NÓBREGA; COUTINHO, 2003). A técnica foi aplicada antes da visita e uma semana após o seu retorno e envolveu apenas os estudantes que aceitaram respondê-la. Na TALP o estudante deve escrever seis palavras que tem relação como a expressão indutora supracitada. Após isso, ele deve escolher entre as seis, uma palavra que 
melhor define (palavra central) e justificá-la. A justificativa da escolha foi tratada de acordo com o DSC. Juntamente com o TALP os estudantes responderam a mais 16 questões objetivas de sim e não.

\section{Discurso do Sujeito Coletivo}

Para avaliar o discurso dos estudantes sobre a importância do turismo para o desenvolvimento local foi gravada uma entrevista semiestruturada, posteriormente transcrita e tratada de acordo com o Discurso do Sujeito Coletivo (DSC, segundo LEFÈVRE; LEFÈVRE, 2005). Foram entrevistados 10 estudantes o $8^{\circ}$ ano e 15 do $9^{\circ}$ ano antes e após participarem da visita orientada. A técnica do DSC foi empregada justamente por dar conta da discursividade, buscando preservá-la em todos os momentos da pesquisa, desde a elaboração das perguntas, passando pela coleta e pelo processamento dos dados até culminar com a apresentação dos resultados. Neste sentido, de acordo com as orientações do DSC, as questões da entrevista semiestruturada foram elaboradas de forma clara, objetiva e na expectativa de levar o entrevistado à produção de um discurso. As questões foram:

1. Você sabe quais são as profissões do turismo? Explique.

2. Você sabe quais são as empresas envolvidas com o turismo?

3. Você sabe quais são os animais predominantes nas matas e rios de bonito?

4. Você sabe quais são os principais rios da região de Bonito?

5. O que significa ecoturismo para você?

\section{Análise dos dados}

Para análise do TALP foi feito um dicionário decorrente das palavras geradas pela expressão indutora e organizada por ordem alfabética. $O$ dicionário foi agrupado e reduzido em função das palavras que apresentaram o mesmo sentido, sinônimo e semântico. As palavras foram tratadas quantitativamente pela frequência de ocorrência relativa das palavras centrais - aquelas apontadas como mais importante - e pelas palavras secundárias - a soma das palavras apontadas da $2^{\underline{a}}$ a $6^{\underline{a}}$ posição de importância. As justificativas pela escolha da palavra central foram analisadas segundo o DSC. Para análise qualitativa do DSC, os discursos (justificativas) foram coletivamente agrupados por palavras e destes extraídas as ideias centrais. Os discursos foram preservados em todos os momentos da pesquisa. A ideia central é um nome ou expressão linguística que revela e descreve, de maneira mais sintética, precisa e fidedigna possível, o sentido de cada um dos discursos analisados e de cada conjunto homogênio de expressões-chave. As questões fechadas, de sim e não, foram tratadas por percentual de respostas. 


\section{Resultados}

\section{As representações do turismo local para os estudantes}

O teste de livre associação de palavras decorrentes da expressão indutora "o turismo em Bonito é..." produziu um dicionário com 67 palavras, porém muitas delas sinônimas e semanticamente próximas. Assim, elas foram agrupadas e reduzidas a 39 palavras. Na Tabela 1 é possível observar as palavras que apresentaram maior ocorrência na resposta dos estudantes.

A palavra central, ou seja, aquela indicada como a mais importante, apresentou um dicionário representado por poucas palavras com elevada ocorrência; "cultura", "importante" e "natureza" foram as representações mais significativas. Após a visita técnica foi observado um dicionário mais variado, porém, as representações mais significativas foram as mesmas.

Por outro lado, as palavras secundárias, ou seja, aquelas apontadas

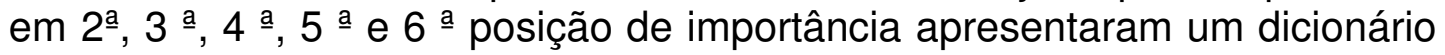
relativamente amplo e com maior equidade na frequência das respostas.

Tabela 1: Frequência de ocorrência de palavras decorrente da expressão indutora "o turismo em Bonito é..." atribuídas pelos 25 estudantes antes e após a atividade de Educação Ambiental.

Table 1: Frequency of occurrence of words resulting from inducing expression "Tourism in Bonito is..." conferred by 25 students before and after the activity for Environmental Education.

\begin{tabular}{|c|c|c|c|c|}
\hline \multirow[b]{2}{*}{ Dicionário } & \multicolumn{2}{|c|}{ P. Central } & \multicolumn{2}{|c|}{ P. Secundárias } \\
\hline & Antes & Após & Antes & Após \\
\hline Aprendizado & 0,0 & 3,8 & 1,6 & 4,8 \\
\hline Atrativo & 12,5 & 3,8 & 7,3 & 8,7 \\
\hline Aventura & 0,0 & 0,0 & 0,8 & 4,8 \\
\hline Bom & 0,0 & 3,8 & 5,6 & 2,4 \\
\hline Bonito & 0,0 & 0,0 & 7,3 & 7,9 \\
\hline Caro & 4,2 & 0,0 & 0,8 & 0,0 \\
\hline Cultura & 20,8 & 11,5 & 3,2 & 2,4 \\
\hline Desenvolvimento & 0,0 & 3,8 & 3,2 & 4,8 \\
\hline Divertido & 0,0 & 0,0 & 7,3 & 7,1 \\
\hline Educacional & 4,2 & 7,7 & 4,8 & 2,4 \\
\hline Emprego & 4,2 & 3,8 & 1,6 & 2,4 \\
\hline Importante & 20,8 & 15,4 & 8,9 & 5,6 \\
\hline Interessante & 4,2 & 3,8 & 1,6 & 0,8 \\
\hline Maravilhoso & 0,0 & 0,0 & 4,0 & 4,0 \\
\hline Natureza & 16,7 & 15,4 & 9,7 & 7,1 \\
\hline Oportunidade & 4,2 & 0,0 & 0,0 & 0,0 \\
\hline Ótimo & 4,2 & 3,8 & 0,8 & 0,8 \\
\hline Preservado & 0,0 & 3,8 & 4,8 & 5,6 \\
\hline Saudável & 4,2 & 3,8 & 0,0 & 0,0 \\
\hline Outras & 0,0 & 15,4 & 26,6 & 28,6 \\
\hline
\end{tabular}

Ao justificarem a escolha da palavra "cultura" como ponto central os estudantes estiveram apoiados nas ideias centrais de "resgate e manutenção da cultura local" e "conhecimento". Tais representações podem ser verificadas nos discursos: 
Conserva as tradições e a economia, conservando a natureza [...] por que você adquire conhecimento [...] você aprende um pouco mais sobre os pontos turísticos e adquire conhecimento [...] fala de povos antigos, de comidas estrangeiras de modo diferente [...] vem do passado por gerações, e também para nós conhecermos um pouco mais sobre a nossa cidade [...] comidas estrangeiras e muitos pontos turísticos.

Após a visita técnica os alunos mantiveram as mesmas ideias centrais, como:

Porque você adquire conhecimento, você fica mais informado [...] adquire mais conhecimento sobre o turismo em nossa cidade [...] são comidas estrangeiras, artesanatos, roupas estranhas e modos antigos.

No estudo realizado por Reis e Bomfim (2012) os entrevistados também apontaram para a cidade de Ouro Preto (MG) como um espaço de cultura, de feitos históricos, cidade patrimônio das artes e da diversidade. Certamente Bonito não apresenta traços históricos tão marcantes como de Ouro Preto, porém a identificação pelos estudantes da importância deste resgate já se torna um fator positivo para o desenvolvimento turístico local. Enquanto Ouro Preto reforça tais afirmações pelo convívio diário das pessoas com monumentos e igrejas do período colonial, na cidade de Bonito as representações mais presentes foram aspectos da comida, artesanato e comportamento.

As representações para a palavra "importante", antes e após a atividade de Educação Ambiental, abrangeram as ideias centrais de "preservação da natureza", "desenvolvimento econômico" e "responsabilidade social" do turismo local. Os discursos que geraram tais ideias foram:
É importante por causa da beleza dos Rios de Bonito, pela preservação das matas [...] gera emprego para a população [...] mostrar os lugares mais lindos que tem em Bonito, o turismo ajuda na geração de empregos [...] ajuda na preservação do nosso meio ambiente [...] renda para melhorias da cidade e com isso gera mais empregos, [...] ajuda a conservar sua fauna [...] para as pessoas saberem a importância do meio ambiente e saber preservar um lugar tão lindo como Bonito [...] para ajudar a cidade melhorar a sua cultura local e trazer várias pessoas para a cidade [...] algo que nos ensina para melhorar o futuro, e é algo muito sério [...] para que os turistas conheçam a nossa região.

Tais discursos e, consequentemente, suas ideias centrais estão amplamente difundidas nas questões fundamentais da sustentabilidade. Dessa forma, é possível observar que os estudantes construíram, conceitualmente, uma imagem de turismo ou ecoturismo ligado a atividades ecologicamente correta, socialmente justa e economicamente viável. Segundo Malta e Barbosa (2013) a menção à capacidade do turismo de 
atuar enquanto agente de desenvolvimento é algo largamente apontado nos trabalhos de turismo, fato que direciona para uma espécie de consenso compartilhado também nos meios políticos e empresarial. Nesse mesmo sentido, o ecoturismo também parece fazer parte deste consenso compartilhado enquanto uma atividade sustentável. Além disso, o ecoturismo tem sido amplamente divulgado e caracterizado por atividades que não implicam em impactos negativos ao meio ambiente e, no entanto, deixa pouco margem para o senso comum para uma análise mais crítica.

Em relação à palavra "natureza" observa-se que a ideia central esteve apoiada na relação de "natureza para o turismo". Neste sentido, os estudantes firmaram uma relação de grande dependência do turismo com o meio ambiente que, no entanto, pôde ser visto como um objeto de consumo "valioso". Os discursos antes da visita foram:

Porque sem natureza Bonito fica sem turismo [...] a natureza é muito importante para o turismo.

Após a visita técnica foi observado:

Porque sem natureza Bonito não tem turismo [...] nós temos que cuidar ainda mais da nossa cidade [...] sempre aprende coisa novas e também é muito lindo o passeio [...] sem ela não teríamos o privilégio de relaxar e se divertir nas belezas naturais de nosso município.

É importante ressaltar que, apesar da palavra "natureza" ter sido indicada isoladamente, ela também apareceu nos discursos gerados pala palavra "importante", o qual reforça esta relação intrínseca do meio ambiente para e pelo turismo. Tais representações também permeiam numa área do conhecimento de grande importância para o ecoturismo, a Educação Ambiental. Neste sentido, torna-se relevante estudar estas concepções e as formas de se trabalhar com elas na Educação Ambiental.

O autor Rodrigues (2010), por exemplo, faz uma análise pela lente da Educação Ambiental Crítica e questiona até que ponto os estudos do meio cumprem os objetivos propostos e até que ponto estes objetivos vão ao encontro do ideal de construção de uma educação para a sustentabilidade. De acordo com o estudo de Oliveira (2011), a conservação de Bonito está garantida, principalmente ao redor dos atrativos turísticos naturais, porém ele salienta que atividades de interpretação ambiental ainda são pouco presente nos programas de turismo da região e não devem ser promovidas como ecoturismo. Evidentemente, a interpretação ou percepção ambiental enquanto elemento construtivo da Educação Ambiental oferece pistas da complexidade do assunto que, no entanto, não deve ser reduzida a uma simples aulas demonstrativa dos recursos naturais. Nesse sentido, a educação ambiental, acaba tendo pouco de educação, confundindo-se com recreação, distração, ocupação do tempo livre (SANDEVILLE-JR; SUGUIMOTO, 2010). 
Conforme apontado pelos autores supracitados, a reavaliação das atividades educativas é fundamental para o desenvolvimento do turismo ecológico e, entretanto, uma tarefa que exige um comprometimento de várias instituições e principalmente o apoio da comunidade local. Uma boa iniciativa pode estar na investigação da relação dos estudantes com 0 turismo local.

\section{A relação dos estudantes com o turismo local}

$\mathrm{Na}$ investigação sobre a relação dos estudantes com o turismo local, apresentada na Tabela 2, foi observado que a maioria se mostrou favorável ao desenvolvimento turístico em Bonito. Porém poucos demonstraram envolvimento direto ou indireto (membros da família) com as atividades turísticas. Generalizando, a metade dos estudantes entrevistados não conhecia as profissões e as empresas envolvidas nos empreendimentos turísticos locais.

Em geral, os estudantes foram favoráveis ao desenvolvimento turístico na região de Bonito, evocando conceitos de sustentabilidade, ou seja, indicando o turismo como uma atividade socialmente justa, economicamente viável e ecologicamente correta. Socialmente justa porque houve grande concordância de que o turismo melhora a qualidade de vida, valoriza a cultura e a comunidade local. Economicamente viável porque gera empregos, auxilia na estrutura e desenvolvimento da cidade. E ecologicamente correto porque não prejudica a natureza e auxilia na conservação ambiental.

No entanto, tais atribuições parecem ser um tanto reducionistas e fundamentadas em uma visão superficial do assunto. Segundo Castro (2003), estas crenças ou tendências a respostas pró-ecológicas ou positivistas têm recebido um elevado acordo por parte do público e é o resultado mais conhecido e mais replicado da literatura. Além disso, a forma de levantamento dos dados, através de questões objetivas baseada em sim e não limitou a análise da percepção dos estudos sobre o desenvolvimento do turismo ecológico local. Nesse sentido, se faz necessário um aprofundamento das relações do turismo com os estudantes locais de forma a explorar como tais conceitos estão sendo abordados em sala de aula e como eles estão sendo realmente vividos pelos estudantes e pela comunidade. O ecoturismo pode ser encarado como uma atividade viável de desenvolvimento dentro da atividade turística, desde que haja consciência sobre a necessidade de enfrentamento das várias questões relacionadas à comunidade local (OLIVEIRA, 2011).

Mesmo após a atividade de Educação Ambiental (visita orientada) os estudantes mantiveram a visão de que o ecoturismo local está se desenvolvendo de maneira sustentável. Isso coloca em questão a própria atividade enquanto elemento de Educação Ambiental para o turismo. Conforme discutido anteriormente, apesar da natureza ser um grande estímulo à sensibilização sobre o ambiente e à sua conservação, ainda existe um espaço a preencher entre essa sensibilização e a verdadeira Educação Ambiental (SANDEVILLE-JR; SUGUIMOTO, 2010). 
Tabela 2: Resposta dos 25 estudantes entrevistados antes e após a visita técnica sobre sua relação com o desenvolvimento turístico local.

Table 2: Response of the 25 students interviewed before and after the technical visit on their relationship with the local tourism development.

\begin{tabular}{|c|c|c|c|c|}
\hline \multirow[b]{2}{*}{ Perguntas } & \multicolumn{2}{|c|}{ Antes } & \multicolumn{2}{|c|}{ Após } \\
\hline & sim & não & $\operatorname{sim}$ & não \\
\hline Alguém da sua família trabalha com turismo? & 7 & 18 & 7 & 18 \\
\hline Você sabe quais são os atrativos turísticos de & & & & \\
\hline Bonito? & 22 & 3 & 23 & 2 \\
\hline Gostaria de aprender mais sobre turismo e meio & & & & \\
\hline ambiente? & 23 & 2 & 25 & - \\
\hline O turismo auxilia no desenvolvimento da cidade? & 25 & - & 25 & - \\
\hline O turismo prejudica a natureza? & 2 & 23 & 1 & 24 \\
\hline O turismo melhora a estrutura da cidade? & 24 & 1 & 25 & - \\
\hline O turismo auxilia na conservação ambiental? & 23 & 2 & 24 & 1 \\
\hline O turismo gera empregos? & 25 & - & 25 & - \\
\hline O turismo melhora a qualidade de vida? & 22 & 3 & 24 & 1 \\
\hline O turismo valoriza a cultura? & 23 & 2 & 25 & 0 \\
\hline O turismo ajuda a comunidade local? & 19 & 6 & 19 & 6 \\
\hline Você sabe quais são as profissões do turismo? & 15 & 10 & 20 & 5 \\
\hline $\begin{array}{l}\text { Você sabe quais são as empresas envolvidas no } \\
\text { turismo? }\end{array}$ & 11 & 14 & 12 & 13 \\
\hline $\begin{array}{l}\text { Sabe quais animais são predominantes em } \\
\text { Bonito? }\end{array}$ & 24 & 1 & 24 & 1 \\
\hline Você sabe quais são os principais rios da região? & 21 & 4 & 25 & - \\
\hline Você sabe o que é ecoturismo? & 20 & 5 & 22 & 3 \\
\hline
\end{tabular}

Segundo Rodrigues (2010), as práticas de educação ambiental ainda seguem, em sua maioria, abordagens ligadas à predominante visão preservacionista, apoiadas em atividades na natureza, compreendida como "meio natural", externo ao ser humano. O mesmo pode estar ocorrendo com as atividades voltadas para promoção do ecoturismo e que, de certa forma, pode estar levando a uma ideia fantasiosa ou amplamente contextualizada de "salvadora" do meio ambiente.

Neste contexto, as abordagens já mencionadas da Educação Ambiental Crítica, baseadas nos ideais da pedagogia crítica defendida em especial por Paulo Freire, sustenta-se na discussão da cotidianidade nas práticas ambientais, para que os alunos possam utilizar o conhecimento sobre o meio ambiente para compreender sua realidade (RODRIGUES, 2010). Vale ainda destacar a capacidade da atividade turística de proporcionar impactos de ordens positivas e negativas para a comunidade receptora, uma vez que, para que os impactos sejam positivos, atrela-se a construção de um equilíbrio e harmonioso processo de promoção do turismo ao exercício do planejamento turístico, nem sempre ao alcance da comunidade receptora (MALTA; BARSOSA, 2013). Assim, será possível trabalhar de forma mais crítica e preparar efetivamente os estudantes para perceber os pontos fortes e fracos das atividades de ecoturismo. 


\section{O conhecimento dos estudantes sobre a vegetação local}

Quando os estudantes foram questionados sobre o tipo de vegetação predominante na região de Bonito observou-se uma diferença representativa nas respostas antes e após a atividade de educação ambiental (Figura 1); as respostas estavam divididas entre vegetação de cerrado e pantanal antes da atividade, porém os estudantes passaram a indicar predominantemente 0 cerrado como representação do bioma de Bonito após a atividade de campo.

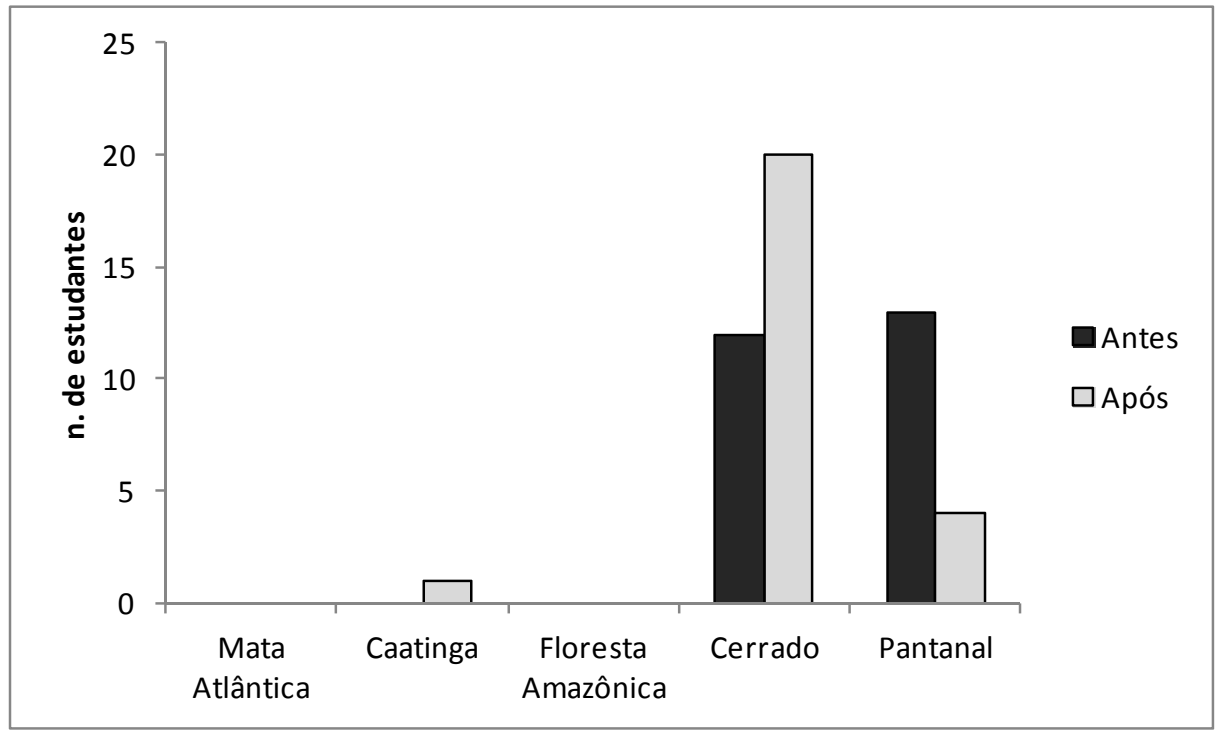

Figura 1: Resposta dos 25 estudantes sobre a vegetação predominante de Bonito (MS).

Figure 1: Answer the 25 students on the predominant vegetation Bonito (MS, Brazil).

A diferença nas respostas identificadas após a visita orientada demonstra que ocorreu um aprendizado representativo dos estudantes em relação às características da vegetação local. De acordo com Fonseca-Filho (2007), quando a educação em turismo consegue promover que o autóctone conheça mais sobre sua localidade, adquirindo conhecimento e novas informações, o mesmo passa a respeita-la mais, além de que, o sentimento de pertencimento e a valorização do lugar aumentam. Mesmo com a proximidade do Pantanal, a vegetação da região de Bonito apresenta características de cerrado. A atividade, no entanto, permitiu a formação de uma identidade que induz o aperfeiçoamento de um raciocínio geográfico mais correto da região.

$\mathrm{Na}$ questão sobre quais são os animais predominantes nas matas e rios de Bonito, foi observado que os estudantes apresentaram conhecimento de uma variedade de espécies, como:

Tem onça pintada, tamanduá, anta, peixe [...] nos rios são sucuri e jacarés, aí em terra é anta, tucano, arara, papagaio [...] eu sei, tem anta, capivara, onça, lombinho, cutia, paca, tucano, arara [...] dourado, pintado, piraputanga, piáu, curimba, caxara, lambari, bagre. 
Os exemplos da fauna citados pelos estudantes demonstram certa familiaridade com o meio ambiente. Tais conhecimentos são de grande relevância em locais onde se pretende criar um elo entre o ecoturismo e a educação ambiental. Segundo Oliveira (2011), atividades de ecoturismo promovem integração ao meio ambiente e com isso uma consciência ambiental a favor da conservação e preservação. Ao saber mais sobre o bioma local e identifica-lo na prática em uma atividade turística, educacional ou comercial, reafirma aos estudantes a ideia de que existe um elo harmônico entre turismo e meio ambiente de grande importância.

O conhecimento expressado nas respostas dos estudantes também caracteriza uma relação afetiva com o meio ambiente. Segundo Sandeville e Suguimoto (2010), para se construir uma consciência de conservação é fundamental que os laços afetivos estejam sendo estimulados, principalmente através do vínculo com aquilo que já se conhece. Sendo o município de Bonito considerado uma cidade pequena e onde o meio urbano e rural não possuem divisão extrema, o convívio com a natureza não é algo fora do cotidiano dos entrevistados. O meio ambiente faz parte de suas histórias e, consequentemente, faz parte do senso comum da comunidade. No entanto, em um lugar onde estes laços são despertados torna-se mais fácil a promoção da educação ambiental, sobretudo em visitas orientadas, para que as mesmas não tenham apenas o enfoque de lazer.

\section{A experiência promovida pela visita técnica}

No questionamento sobre a experiência dos estudantes em participar da visita orientada foi observado grande receptividade e satisfação por parte deles. Todos estiveram representados na ideia central de que a "atividade conciliou conhecimento e entretenimento". Essa ideia reafirma os conceitos de afetividade e efetividade descritos anteriormente.

Esse tipo de experiência consegue despertar nos alunos a sensibilização pelas questões ambientais através da educação em conjunto com o lazer. Esse é o grande desafio da atividade de ecoturismo, sendo feita por turistas ou autóctones, é importante transformar a sensibilização em aprendizagem efetivamente, caso contrário o conhecimento transferido pela vivência na natureza pode ser superficial (SANDEVILLE-JR; SUGUIMOTO, 2010).

Tais ideias estão representadas nos discursos:

O passeio é ótimo e ajuda a ter mais contato com a natureza [...] muito legal, interessante e divertido [...] adquiri muito conhecimento, conhecemos rios, cachoeiras, e sem falar na vegetação pois eu gostei muito do passeio [...]quero fazer de novo[...] aprendi muitas coisas com as explicações dos guias e com a palestra. [...] aprendi muitas coisas, tipo, cuidar da natureza, preservar o nosso meio ambiente [...] muito legal, pois foi o primeiro lugar que eu visitei. 
É relevante identificar que o beneficio da visita orientada foi além de promover o conhecimento sobre as características do turismo local e da vegetação. Também foi possível promover a educação ambiental em consonância com o bem estar (entretenimento). Neste sentido, Oliveira (2011) destaca que a atividade ecoturística realizada com a comunidade local implica em educar através do contato com áreas naturais e, através disso, consegue proporcionar transformações comportamentais, ampliar 0 autoconhecimento e o respeito ao outro.

Além de todos os aspectos positivos mencionados com a atividade, a experiência também permitiu o resgate da identidade da coletividade, através da afinidade e forte interação que os estudantes demonstraram com o meio ambiente. Castro (2008) afirma que quando a diversidade de um lugar é reconhecida por seu povo permite que os mesmos se reconheçam como um grupo, fortalecendo suas particularidade e essência.

\section{Considerações finais}

Através da aplicação do teste livre de palavras foi observado que os estudantes estão conscientes da relação direta e dependente entre natureza e turismo. Porém, além desta constatação, foram relevantes também as citações em relação aos aspectos culturais da região, que não são destaques no turismo praticado em Bonito. Isso demonstra que a comunidade, representada nessa pesquisa pelos estudantes, acha importante e valoroso as características dos artesanatos, comportamentos e comidas locais. No entanto, é de grande importância que esses aspectos sejam sempre cultivados para que os destinos turísticos não fiquem com características homogêneas e simplesmente seja uma mercadoria a ser consumida (OLIVEIRA, 2011).

A preocupação com o turismo local, mesmo que indiretamente, é perceptiva através dos conceitos sustentáveis evocados pelos alunos, indicando que o tripé social, cultural e econômico é fundamental para o processo turístico. A relação direta dos estudantes com o turismo foi superficial, visto que cursam uma disciplina específica sobre o assunto. Porém, com a inserção de visitas técnicas regulares, a perspectiva é que essa realidade possa mudar, facilitando o aprendizado sobre as questões do turismo, ao mesmo tempo em que a Educação Ambiental é trabalhada.

O estudo constata que, para que o conhecimento seja realmente obtido através da visita é necessário despertar a sensibilização quanto às questões ambientais. Assim, a atividade precisa ser feita de acordo com a realidade local e em contato direto com o meio ambiente.

Desse modo, é possível concluir que através das metodologias utilizadas e da atividade em campo, foi alcançado os objetivos propostos pela pesquisa e percebido que ações de cunho ambiental precisam ser feitas regularmente nas escolas, pois isoladamente e superficial não surgem efeitos para mudar comportamentos e modos de vida. Além disso, o desenvolvimento de atividades técnicas orientadas, assim como do presente estudo, possibilitará, mesmo que sutilmente, a promoção dos aspectos culturais, do respeito ao próximo e a união da comunidade. 


\section{Referências bibliográficas}

BRASIL, Ministério do Turismo. Política Nacional de Turismo, 1992.

BONITO. Projeto de Lei Ordinária n.16, de 09 de junho de 2006. Dispõe sobre a obrigatoriedade da disciplina "Noções Básicos de Turismo" no currículo das escolas da Rede Municipal de Ensino de Bonito-MS, e dá outras providências. Estado de Mato Grosso do Sul, Câmara Municipal de Bonito. Disponível em: $<$ http://www.camarabonito.com.br/proposicoes/projeto-de-lei-ordinaria/anterior2009/projetos-de-lei-ordinaria-n-16-ano-2006>. Acesso em: 27 de jan. 2014.

CASTRO, C.S. Educação para o Turismo: Preservação da identidade regional e respeito À cultura imaterial. Fênix - Revista de História e Estudos Culturais, v. 5 , n. 4, p. 1-12, 2008.

CASTRO, P. Pensar a natureza e o ambiente - alguns contributos a partir da Teoria das Representações Sociais. Estudos de Psicologia, Campinas, v. 8, n. 2. p. 263-271, 2003.

FASSINI, D.; LACERDA, L. Cartilha Projeto Matas Ciliares: cuidando das águas e matas do rio Mimoso. 1 ed - Bonito: IASB, 2009

FONSECA FILHO, A.S. Educação e Turismo: Reflexões para Elaboração de uma Educação Turística. Revista Brasileira de Pesquisa em Turismo, v. 1, n. 1, p. 5-33, 2007.

GRECHI, D.C.; LOBO, H.A.S.; MARTINS, P.C.S.; LUNAS, J.R.S. Autogestão e controle de visitantes: voucher unificado em Bonito, MS. In: PHILIPPI-JR, A.; RUSCHMANN, D.V.M. (Editores). Gestão ambiental e sustentabilidade no turismo. Barueri, SP: Manole, cap. 40. p. 913-931, 2010.

LEFÈVRE, F.; LEFÈVRE, A.M.C. O discurso do sujeito coletivo: um novo enfoque em pesquisa qualitativa (desdobramentos). Caxias do Sul: Editora Educs, 256 p., 2005.

MALTA, G.A.P.; BARBOSA, M.F.P. Turismo e desenvolvimento: reflexões acerca de uma complexa relação. Revista Brasileira de Ecoturismo, São Paulo, v. 6, n. 5, p. 862-895, 2013.

MARIANI, M.A.P. Turismo e meio ambiente no paraíso das águas. Campo Grande: UCDB, 2003.

NÓBREGA, S.M.; COUTINHO, M.P.L. O teste de associação livre de palavras. In: COUTINHO, M.P.L.; LIMA, A.S., OLIVEIRA, F.B.; FORTUNATO, M.L. (Orgs.). Representações sociais: abordagem interdisciplinar, João Pessoa: Universitária, p. 67-77, 2003.

OLIVEIRA, C. F. Ecoturismo como prática para o desenvolvimento socioambiental. Revista Brasileira de Ecoturismo, São Paulo, v. 4, n. 2, p. 184-195, 2011.

PELICIONI, M.C.F.; TOLEDO, R.F. Educação para o turismo: Turismo e comunidade. In: PHILIPPI-JR, A.; RUSCHMANN, D.V.M. (Editores). Gestão ambiental e sustentabilidade no turismo. Barueri, SP: Manole, cap. 14. p. 301-312, 2010.

REIS, A.M. da S.; BOMFIM, N.R. Representações Sociais da Comunidade sobre o Festival de Inverno de Ouro Preto, Minas Gerais (Brasil) a partir da Evocação Livre de Palavras. Turismo \& Sociedade, Curitiba, v. 5, n. 1, p. 252274, 2012. 
RODRIGUES, A.B. Turismo - Desenvolvimento Local. São Paulo: Hucitecc, 2001.

RODRIGUES, C. Observando os "estudos do meio" pela lente da educação ambiental crítica. Revista Eletrônica do Mestrado em Educação Ambiental, Rio Grande, v. 24, n. 1, p. 503-517, 2010.

RUSCHMANN, D.; SOLHA, K.T. Turismo: Uma visão empresarial. São Paulo: Manole. 2004

SALUSTIANO, S. F. M.; FREITAS, M. J. C. C.; MARÓN, J. R. L.; MAGALHÃES, H. G. D. A Educação Ambiental e o turismo Ecológico. Educação Temática Digital, Campinas, v.9, n.1, p. 1-12, 2007.

SANDEVILLE-JR, E.; SUGUIMOTO, F.T. Ecoturismo e (Des)Educação Ambiental. Revista Brasileira de Ecoturismo, São Paulo, v.3, n.1, p.47-60, 2010.

WWF, Brasil. Turismo Responsável: Manual para políticas locais. Brasília: UNB. 2004.

Clara Antunes Cardoso: Universidade Estadual de Mato Grosso do Sul, Dourados, MS, Brasil.

E-mail: clara.boia@hotmail.com

Link para o currículo Lattes: http://lattes.cnpq.br/2046118484800767

Emerson Machado de Carvalho: Universidade Estadual de Mato Grosso do Sul, Dourados, MS, Brasil.

E-mail: carvalho.em@gmail.com

Link para o currículo Lattes: http://lattes.cnpq.br/7341724276580365

Luciana Ferreira da Silva: Universidade Estadual de Mato Grosso do Sul, Dourados, MS, Brasil.

E-mail: lucianafsilva@uol.com.br

Link para o currículo Lattes: http://lattes.cnpq.br/6097823498734817

Data de submissão: 22 de março de 2014

Data de recebimento de correções: 22 de março de 2014

Data do aceite: 29 de abril de 2014

Avaliado anonimamente 